\title{
Expression of artemin and GFRa3 in an animal model of migraine: possible role in the pathogenesis of this disorder
}

\author{
Hai-Qiong Shang 1,2, Yan Wang 1,4, Yan-Yan Mao 1,2, Li-Gang Kong ${ }^{1,2}$, Gao-Ying Sun ${ }^{2,3}$, Lei Xu1', Dao-Gong Zhang ${ }^{1}$, \\ Yue-Chen Han ${ }^{1}$, Jian-Feng Li $i^{2,3}$, Hai-Bo Wang ${ }^{1,2,3}$ and Zhao-Min Fan ${ }^{1 *}$
}

\begin{abstract}
Background: Neurotrophic factors have been implicated in hyperalgesia and peripheral levels of these molecules are altered in migraine pathophysiology. Artemin, a vasculature-derived neurotrophic factor, contributes to pain modulation and trigeminal primary afferent sensitization through binding its selective receptor GFRa3. The distribution of artemin and GFRa3 in the dura mater raises an anatomy supports that they may be involved in migraine. In this study we evaluated the expression of artemin and GFRa3 in an animal migraine model that may be relevant for migraine.
\end{abstract}

Methods: In this study, using a rat migraine model by administration of nitroglycerin (NTG), we investigated the expression of artemin in the dura mater and GFRa3 in the trigeminal ganglia (TG) by means of quantitative reverse transcription-polymerase chain reaction, western blot and immunofluorescence labeling.

Results: Artemin immunoreactivity was found in the smooth muscle cells of dural vasculature and GFRa3 was present in cytoplasm of TG neurons. The mRNA levels of artemin and GFRa3 were significantly elevated after NTG treatment at 2 and $4 \mathrm{~h}$ respectively $(P<0.05)$. The expression of artemin protein was increased at $4 \mathrm{~h}$ and continually up to $8 \mathrm{~h}$ in the dura mater following NTG administration $(P<0.05)$. The expression of GFRa3 protein was elevated at $4 \mathrm{~h}$ and continually up to $10 \mathrm{~h}$ in the TG following NTG administration $(P<0.05)$.

Conclusion: The findings suggest that artemin and GFRa3 play an important role in the pathogenesis of migraine and may represent potential therapeutic targets for the treatment of migraine.

Keywords: Migraine, Artemin, GFRa3, Dura mater, Trigeminal ganglia

Abbreviations: CGRP, Calcitonin gene related peptide; DRG, Dorsal root ganglia; GDNF, Glial cell line-derived neurotrophic factor; GFRa3, GDNF family receptor alpha 3; NO, Nitric oxide; NS, Normal saline; NTG, Nitroglycerin; PBS, Phosphate-buffered solution; qRT-PCR, Quantitative real-time reverse transcription-polymerase chain reaction; TG, Trigeminal ganglia; TRPV1, Transient receptor potential vanilloid 1; a-SMA, a-smooth muscle actin

\section{Background}

Migraine is a common neurovascular disorder characterized by recurrent attacks of typically throbbing and unilateral headache, which affects up to $20 \%$ of the population [1]. However, its pathophysiology has not yet been fully elucidated. To date, on the basis of

\footnotetext{
* Correspondence: fanzment@outlook.com

'Department of Otolaryngology-Head and Neck Surgery, Shandong

Provincial Hospital Affiliated to Shandong University, Jinan 250021, People's

Republic of China

Full list of author information is available at the end of the article
}

clinical observations and experimental studies, several theories have been proposed for the mechanisms underlying this disorder. In particular, one theory, which focuses on the trigeminovascular system, has been widely accepted in migraine pathogenesis $[2,3]$. Many studies indicate that activation of peripheral trigeminal nociceptors in the dura mater results in the release of neuropeptides and neurotrophins, which are related to the generation and modulation of migraine pain $[4,5]$.

In recent years, artemin, a member of the glial cell line-derived neurotrophic factor (GDNF) family, has 
aroused considerable interest because it not only modulates the development and function of sensory neurons $[6,7]$, but also participates in the pathophysiology of peripheral inflammation and pain hyperalgesia [8]. Artemin exerts its influence on intracellular signaling pathways via binding to the receptor complex of GDNF family receptor alpha 3 (GFR $\alpha 3$ ) and ret [9]. GFR $\alpha 3$, a highly selective receptor for artemin, is co-expressed with the transient receptor potential vanilloid 1 (TRPV1) in the dorsal root ganglia (DRG) and trigeminal ganglia (TG) $[10,11]$. TRPV1, a calcium permeable ion channel, is activated by heat and capsaicin, and is considered to play a major role in the pathogenesis of migraine $[12,13]$. In addition, the detection of the distribution of artemin and its receptor GFR $\alpha 3$ in the dura mater of rats suggests that artemin may contribute to migraine pain by the sensitization of dural afferents [11].

It is known that systemic administration of nitroglycerin (NTG), a nitric oxide (NO) donor, can induce delayed headaches in both migraneurs and healthy people [14], and NTG-treated rodents have been found to be predictive animal models of migraine [15]. Previous reports have shown that the rat migraine model triggered by NTG present vasodilation of the meningeal vessels and lead to the release of proinflammatory substances [16]. In this regard, the present study was designed to evaluate the expression of artemin in the dura mater and GFR $\alpha 3$ in the TG following NTG administration, so as to explore the possible mechanisms of artemin and GFR $\alpha 3$ underlying the pathogenesis of migraine.

\section{Methods}

Male wistar rats (weight 260-300 g) were purchased from Animal Centre of Shandong University (Jinan, China) and maintained in a humidity-controlled as well as thermoregulated vivarium with a 12-h light/dark cycle. The animal care and experimental protocol were approved by the Animal Care Committee of Shandong University, PR China (NO. ECAESDUSM 20123011).

Eighty wistar rats were stochastically divided into three groups: normal control, normal saline (NS) control, and the NTG groups. NTG at dose of $10 \mathrm{mg} / \mathrm{kg}$ was injected cervical subcutaneously to set up the rat model of migraine [17]. In the NS group, rats were treated with isotonic saline using the same volume as NTG. At different time points after NTG or NS treatment, rats were anaesthetized with $10 \%$ chloral hydrate $(4 \mu \mathrm{l} / \mathrm{g})$. Then the temporal bones were removed and the dura was carefully dissected out. After removing the brain halves, the TG tissues were separated from the cranial base. Some tissue samples were quickly frozen at $-80{ }^{\circ} \mathrm{C}$ for further western blot analysis and qRT-PCR, others were fixed in $4 \%$ paraformaldehyde for immunofluorescent staining.

\section{Quantitative reverse transcription-polymerase chain reaction (qRT-PCR)}

Total RNA was extracted from the dura mater and TG using the Trizol Reagent (Invitrogen, Gaithersburg, USA) according to the manufacturer's instructions. For each sample, $1 \mu \mathrm{g}$ total RNA was reverse transcribed using the ExScript RT reagent kit (TaKaRa, Dalian, China). Using SYBR Green PCR kits, qPCR was performed on an Eppendorf AG 22331 Hamburg machine (Germany). Forward and reverse primer sequences applied in realtime PCR were as follows: artemin-F: $5^{\prime}$-ACTCATTCC TGGTTGCCTTCT-3'; artemin-R: 5'-GGTCTTCACC TTCCATTCAGA-3'; GFR $\alpha 3-F$ : 5'-ACTCATTCCTGG TTGCCTTCT-3'; GFR $\alpha 3-R:$ 5'-GGTCTTCACCTTC CATTCAGA-3'; $\beta$-actin-F: $5^{\prime}$-GTGGGGCGCCCCAG GCACCA-3'; $\beta$-actin-R: $5^{\prime}$-CTCCTTAATGTCACG CACGATTT-3'; GAPDH-F: 5'-GTGGGGCGCCCCA GGCACCA-3'; GAPDH-R: 5'-CTCCTTAATGTCACG CACGATTT-3'. The calculated number of specific transcripts was normalized by $\beta$-actin or GAPDH. The realtime value for each sample was averaged and compared by using the CT method. The amount of target RNA $\left(2^{-\Delta \Delta C t}\right)$ was normalized both with the endogenous $\beta$-actin or GAPDH reference $(\Delta \mathrm{Ct})$ and theamount of target gene in control sample, which was set as the calibrator at 1.0.

\section{Western blot analysis}

Total protein was extracted using radioimmune precipitation buffer protein lysis buffer according to protocols (Beyotime, Shanghai, China). The protein content of the samples was measured by means of the BCA protein assay kit (Beyotime, Shanghai). The protein samples were denatured and separated by $10 \%$ sodium dodecyl sulfatepolyacrylamide gel electrophoresis and transferred onto nitrocellulose membranes. The nitrocellulose membranes were blocked for $1 \mathrm{~h}$ at room temperature in $5 \%$ skimmed dried milk. Then the membranes were incubated with primary antibodies including: rabbit antibody to GFR $\alpha 3$ (1:1000, Abcam Systems, USA), rabbit antibody to artemin (1:200, Abbiotec, San Diego) and mouse antibody to $\beta$ actin (1:1000, Santa Cruz Biotechnology, USA) in TBST containing $3 \%$ fat-free dry milk for $1 \mathrm{~h}$ at room temperature and overnight at $4{ }^{\circ} \mathrm{C}$. After washing 3 times with TBST, the membranes were incubated with the secondary donkey anti-rabbit or anti-mouse IgG antibodies (1:5000, Santa Cruz, USA) at room temperature for $1 \mathrm{~h}$. Finally, the immunoblots were detected using an ECL kit (Santa Cruz, USA) and visualized after exposure to X-ray films. The relative optical density ratio was calculated with the Image J software by comparison to GAPDH or $\beta$-actin.

\section{Immunofluorescence staining}

Tissues were fixed in $4 \%$ paraformaldehyde at $4{ }^{\circ} \mathrm{C}$ for $24 \mathrm{~h}$, followed by incubated in $30 \%$ sucrose for $24 \mathrm{~h}$, 
embedded in optimum cutting temperature compound for $24 \mathrm{~h}$, quickly frozen with liquid nitrogen, and cut into $6 \mu \mathrm{M}$ sections using a cryostat (Leica CM 1850, Nussloch, Germany). For immunofluorescence, samples were washed in $0.01 \mathrm{M}$ PBS and blocked in PBS containing $0.3 \%$ Triton X-100 (Sigma, USA) and $10 \%$ donkey serum (NQBB, USA) for $1 \mathrm{~h}$ at room temperature and incubated in primary antibodies overnight at $4{ }^{\circ} \mathrm{C}$. The following antibodies were used: goat antibody to GFR $\alpha 3$ (1:50, R\&D Systems, USA), rabbit antibody to artemin (1:50, Abbiotec, San Diego) and mouse antibody to $\alpha-$ smooth muscle actin ( $\alpha$-SMA) (1:50, Dako Cytomation, Germany), After being washed fully in PBS, samples were incubated with secondary antibodies (1:1000, Invitrogen, USA) and 49,6-diamidino-2-phenylindole (DAPI) (1:1000, Molecular Probes, USA) in PBS at room temperature for $1 \mathrm{~h}$. Then rinsed in PBS for $30 \mathrm{~min}$. Immunofluorescent samples were visualized with an inverted DMI 400CS confocal microscope (Leica, Germany).

\section{Statistical analysis}

The statistical analyses were performed using SPSS 17.0 software (SPSS Inc., Chicago, ILL, USA). Data were expressed as mean \pm standard error of the mean (SEM). One-way Analysis of variance (ANOVA) was used for statistical analysis and $P<0.05$ was considered statistically significant.

\section{Results}

\section{Expression of artemin in the dura mater}

In consideration of NTG-induced delayed onset inflammation in migraine model rats, the mRNA expression of artemin in the dura mater was detected after NTG or NS administration for 2, 4 and $6 \mathrm{~h}$ each. As shown in Fig. 1, the mRNA level of artemin was significantly elevated at 2 and $4 \mathrm{~h}$ after NTG administration compared to the normal control group. There was no significant difference in artemin mRNA expression between the NS control group and the normal control group.

Four time points $(2,4,6$ and $8 \mathrm{~h})$ were chosen to evaluate the protein level of artemin in the dura mater following NTG or NS injection. As shown in Fig. 2, the expression of artemin protein was low in both normal control group and NS control group. However, the protein expression of artemin in the dura of rats after NTG injection from 4 to $8 \mathrm{~h}$ was dramatically increased compared with that in the normal control rats.

\section{Expression of GFRa3 in the TG}

The mRNA expression of GFR $\alpha 3$ in the TG was detected after NTG or NS administration for 2, 4 and 6 h each. As shown in Fig. 3, the mRNA level of GFR $\alpha 3$ in the TG was markedly increased at the 4-h time point after NTG administration compared to the normal control group.

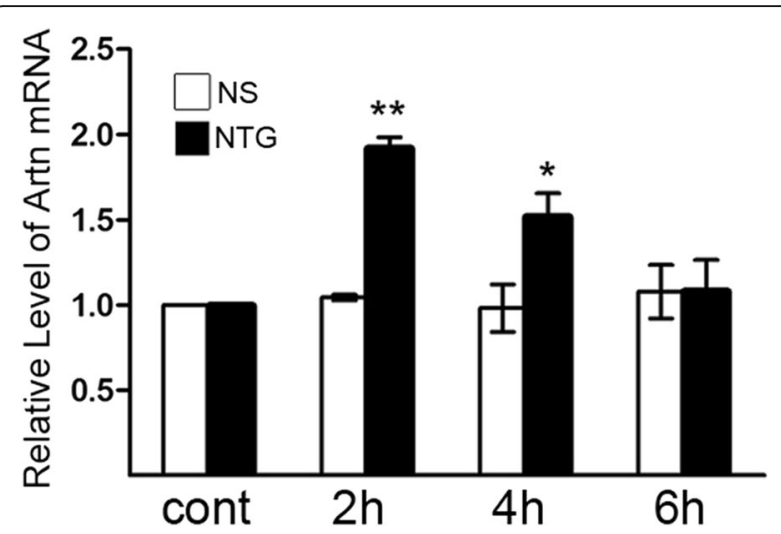

Fig. 1 Alteration of artemin mRNA expression in the dura mater after NTG treatment. The expression of artemin (Artn) mRNA was significantly increased at $2 \mathrm{~h}, 4 \mathrm{~h}$ following NTG treatment compared with that in the normal control group $\left({ }^{* *} P<0.01,{ }^{*} P<0.05\right)$. No significant change in NS control group was observed compared to normal control group. The data shown here were mean \pm SEM of three separate experiments

There was no significant difference in GFR $\alpha 3$ mRNA expression between the NS control group and the normal control group.

Five time points $(2,4,6,8$, and $10 \mathrm{~h})$ were chosen to evaluate the protein level of GFR $\alpha 3$ in the TG after

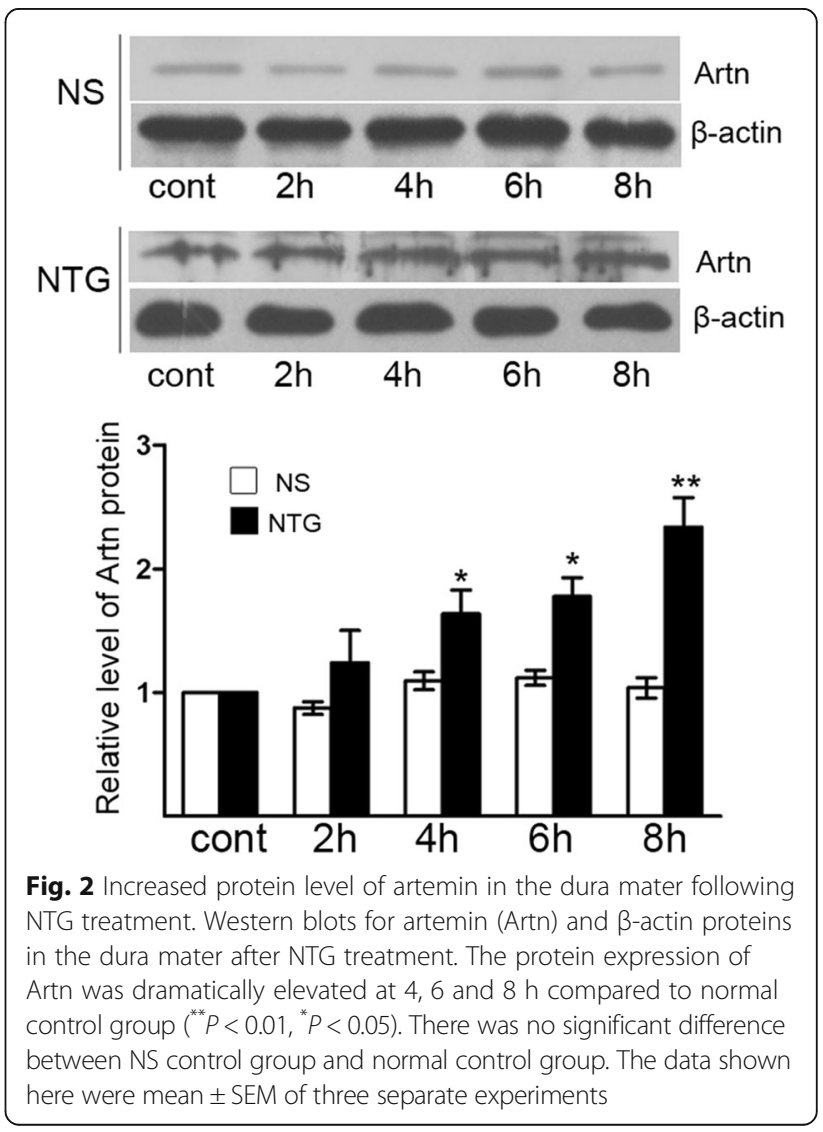




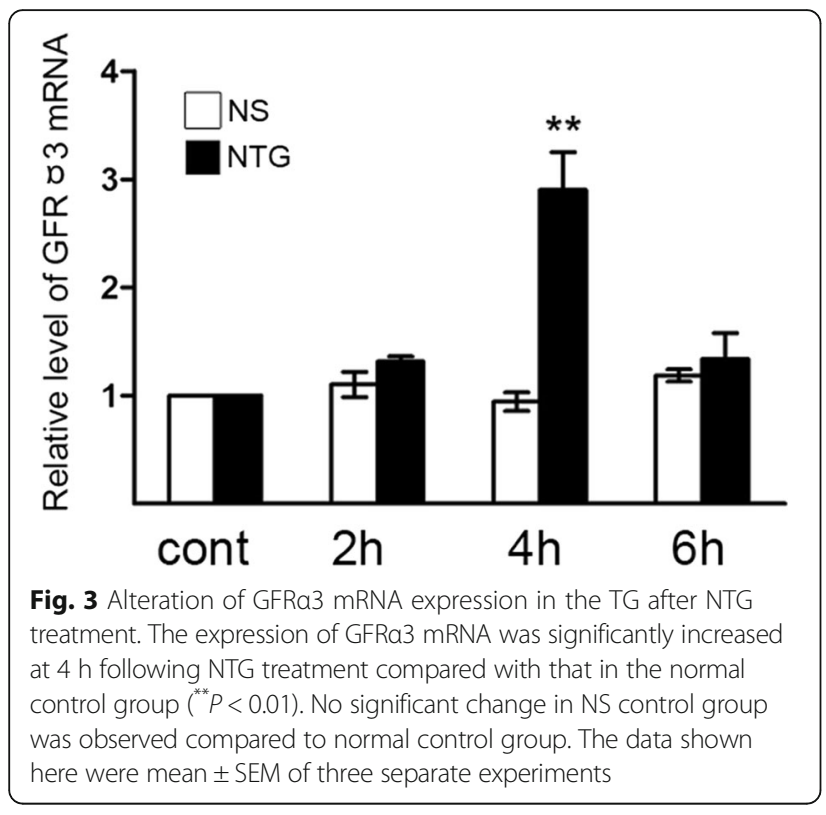

NTG or NS injection. As shown in Fig. 4, the expression of GFR $\alpha 3$ protein was low in both normal control group and NS control group. However, the protein expression of GFR $\alpha 3$ in the TG after NTG injection from 4 to $10 \mathrm{~h}$ was markedly increased compared with that in the normal control rats.

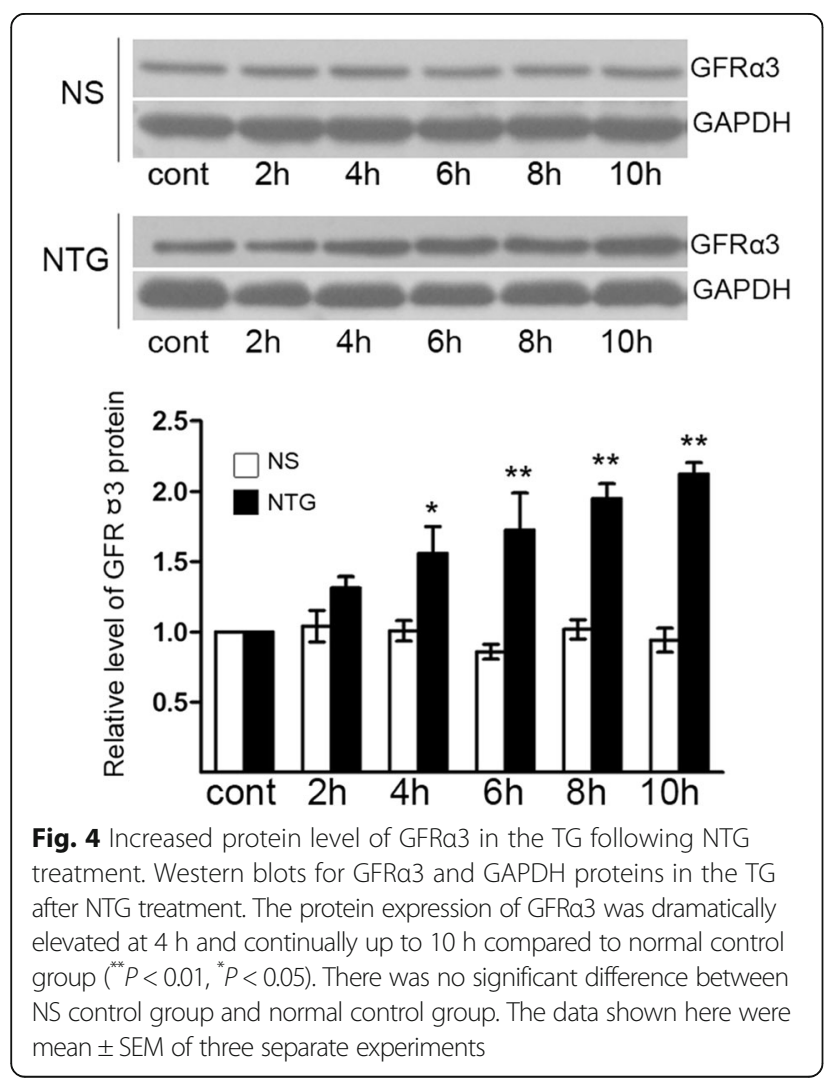

Immunofluorescence labeling for artemin and GFRa3

Double immunofluorescence labeling proved the colocalization of artemin and $\alpha$ - smooth muscle actin $(\alpha-$ SMA), a maker for smooth muscle cells, on the dural blood vessels. Additionally, the immune positive signal of artemin that it was observed after NTG was obviously enhanced than that of NS-treated control rats. Meanwhile, some artemin was secreted out the smooth muscle cells of dural vasculature (Fig. 5a-f).

Double immunofluorescence showed that low level of GFR $\alpha 3$ was present in the cytoplasm of TG neurons. In addition, an increased number of GFR $\alpha 3$ immunoreactivity neurons in the TG were observed in NTG group compared to the NS control group (Fig. 5j-1).

\section{Discussion}

NTG, an exogenous NO donor, is known to induce migraine-like headache in migraineurs and rodents [18]. Systemic administration of NTG has been reported to cause inflammation and sensitization of primary afferents of the trigeminovascular system [19-21]. In this study, we explored the locations and expression of artemin and its selective receptor GFR $\alpha 3$ in an animal model of migraine, with special attention given to their possible involvement in the pathogenesis of migraine.

In recent years, the role of artemin in mediating neuropathic and inflammatory pain has been paid much attention $[8,22]$. The level of artemin is known to be elevated after peripheral inflammation or nerve injury $[7,8]$. It has been demonstrated that infusion of NTG lead to vasodilation of the meningeal blood vessels and then modulate the inflammatory factors release [23]. In this study, we found that both the mRNA and protein levels of artemin in the dura mater were up-regulated following NTG administration. In the time course of NTG-induced mRNA and protein expression levels of artemin we found a delayed response, which was consistent with delayed meningeal inflammation of earlier studies. In their reports, migraine attacks do not occur immediately after NTG administration with the vasodilatory effects of the drug, but rather after 2 to $6 \mathrm{~h}[21,24]$. The trends of the mRNA expression apparently were mismatched with that of protein expression, which might be due to the delayed expression from mRNA to functional receptor protein. In addition, artemin was shown to be located in the smooth muscle cells of dural vasculature, which was in agreement with a study by McIlvried, who firstly reported the expression of artemin in the dura mater of rats [11]. Moreover, in a migraine model, our findings supplied the firsthand evidence that the immunfluorescence intensity of artemin was obviously up-regulated and a certain amount of artemin was secreted out the smooth muscle cells of the dural vascular, 

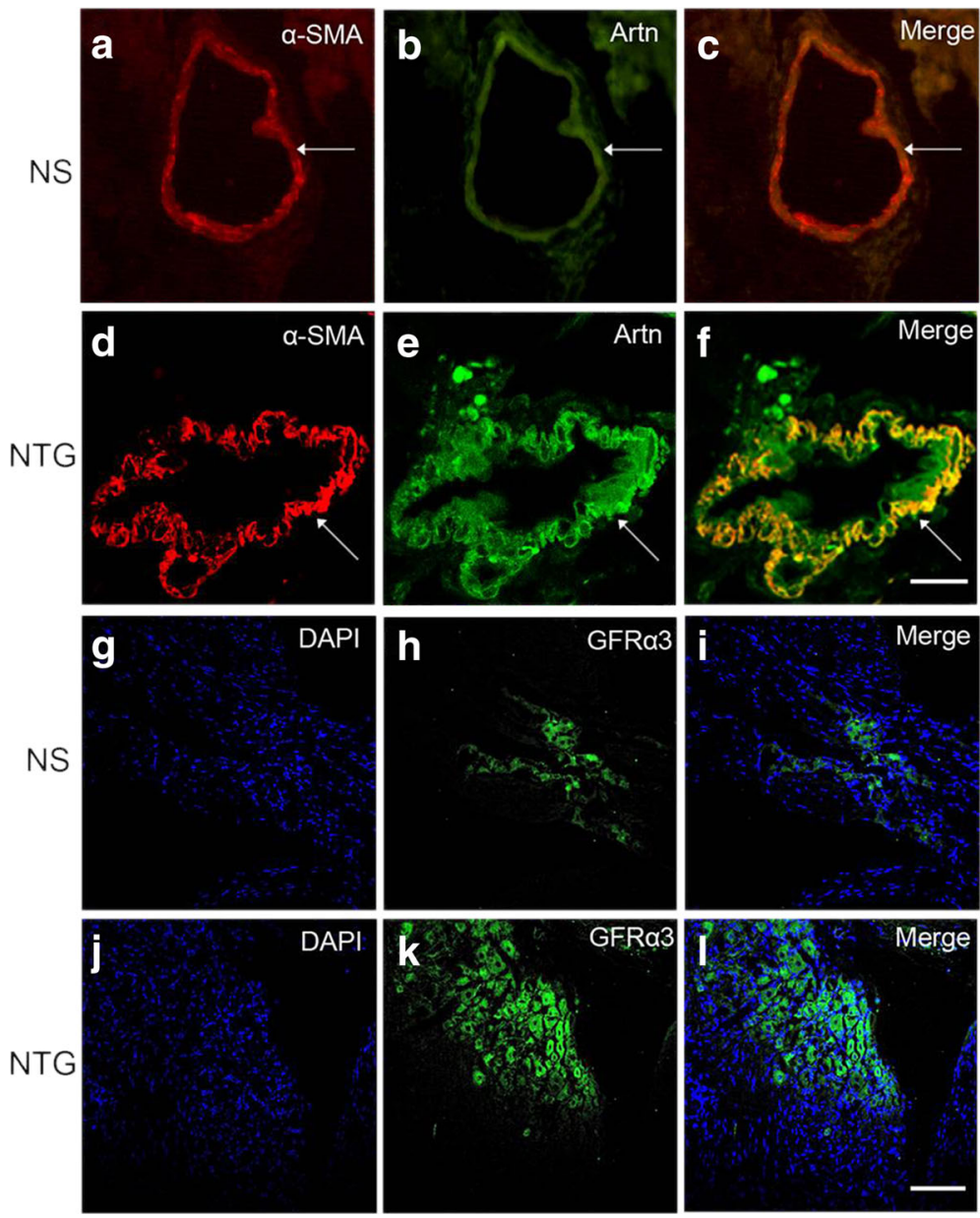

Fig. 5 Immunostaining of artemin in the dura mater and GFRa3 in the TG after NTG treatment. a-c Immunohistochemical staining for a-SMA (red) and artemin (Artn, green) in the dura mater of NS control group. d-f Artemin was strongly expressed in the dura mater after NTG treatment. $\mathbf{g}$-i Immunohistochemical staining for DAPI (blue) and GFRa3 (green) in the TG of NS control group. $\mathbf{j}-\mathbf{I}$ The number of GFRa3-positive neurons was elevated after NTG treatment. c, f, i, I The same field of merged vision. Scale bar $=100 \mu \mathrm{m}$

indicating that the release of artemin from vasculature may contribute to the dural inflammation of migraine pain.

Artemin exerts its roles in intracellular signaling pathways through the receptor complex of ret and GFRa3, and recent studies suggest that GFRa3 was present in trigeminal afferents that innervate the dura $[9,11]$. To further explore the possible roles of artemin in migraine, the alterations in its selective receptor GFR $\alpha 3$ in response to NTG were continually determined. We found that both the mRNA and protein levels of GFR $\alpha 3$ in the TG were substantially up-regulated as a result of the NTG injection. Meanwhile, the number of GFR $\alpha 3$ immunoreactive TG neurons was increased after NTG treatment, indicating that the release of artemin from the vascular smooth muscle cells may activate the peripheral trigeminal nerve via binding GFR $\alpha 3$ in a rat migraine model. Some observations have shown that GFR $\alpha 3$ appeared to be present in similar subpopulations of nociceptive afferents in the TG $[10,25]$, which suggests that artemin and GFR $\alpha 3$ might play a particularly important role in nociceptive processing in the trigeminal system and consequently contribute to the pathology of migraine.

Previous studies have reported that overexpression of artemin in skin and tongue enhances expression of nociceptor TRPV1 in DRG and TG, thereby leading to behavioral and oral sensitivity $[8,26]$. Moreover, activation of TRPV1 has been shown to promote the release of calcitonin gene-related peptide (CGRP) from trigeminal nerve terminals, which contribute to the neurogenic inflammation in the initiation of a migraine attack [27, 28]. However, other studies suggest that TRPV1 has no effect on the pathogenesis of migraine and TRPV1 antagonists are not effective for migraine treatment [29-31]. Thus, the role of the TRPV1 in migraine pain is still controversial to date, and the downstream regulatory mechanisms underlying the actions of artemin and GFR $\alpha 3$ on migraine pain require to be studied further. 


\section{Conclusion}

In summary, our study revealed that the enhanced activities of artemin and GFR $\alpha 3$ might be critical processes in migraine pathogenesis and serve as the possible key factor in inducing migraine pain. Taken together, artemin and its selective receptor GFR $\alpha 3$ might be novel targets for therapeutic strategies of migraine.

\section{Acknowledgments}

This study was supported by National Natural Science Foundation of China (No: 81170907/H1303), the Foundation of Science and Technology of Shandong Province (No: 2007GG2002), the 12th Five-Year National Key Technologies R \& D Program (No: 2012BAl12B01), and Youth Fund Project of Shandong provincial Medical technology development plan (No: ZR2015HQ006).

\section{Authors' contributions}

ZMF and HBW instructed the experiments. LX, DGZ, YCH contributed to the design of study. HQS, YW and LGK performed the experiments. HQS and YW analyzed the data and drafted the manuscript. YYM, GYS and JFL revised the manuscript. All authors read and approved the final manuscript.

\section{Competing interests}

The authors declare that they have no competing interests.

\section{Author details}

${ }^{1}$ Department of Otolaryngology-Head and Neck Surgery, Shandong Provincial Hospital Affiliated to Shandong University, Jinan 250021, People's Republic of China. 'Shandong Provincial Key Laboratory of Otology, Jinan 250022, People's Republic of China. ${ }^{3}$ Institute of Eye and ENT, Shandong Provincial Hospital Affiliated to Shandong University, Jinan 250022, People's Republic of China. ${ }^{4}$ Department of Otolaryngology, People's Hospital of Rizhao, Rizhao 276800, People's Republic of China.

Received: 14 May 2016 Accepted: 1 September 2016

Published online: 06 September 2016

\section{References}

1. Haut SR, Bigal ME, Lipton RB (2006) Chronic disorders with episodic manifestations: focus on epilepsy and migraine. Lancet Neurol 5:148-57

2. Pietrobon D, Striessnig J (2003) Neurobiology of migraine. Nat Rev Neurosci 4:386-98

3. Boyer N, Dallel R, Artola A, Monconduit L (2014) General trigeminospina central sensitization and impaired descending pain inhibitory controls contribute to migraine progression. Pain 155:1196-205

4. Levy D (2009) Migraine pain, meningeal inflammation, and mast cells. Curr Pain Headache Rep 13:237-40

5. Giniatullin R, Nistri A, Fabbretti E (2008) Molecular mechanisms of sensitization of pain-transducing P2X3 receptors by the migraine mediators CGRP and NGF. Mol Neurobiol 37:83-90

6. Wang S, Elitt CM, Malin SA, Albers KM (2008) Effects of the neurotrophic factor artemin on sensory afferent development and sensitivity. Sheng $L$ Xue Bao 60:565-70

7. Jankowski MP, Rau KK, Soneji DJ, Anderson CE, Koerber HR (2010) Enhanced artemin/GFRalpha3 levels regulate mechanically insensitive, heat-sensitive C-fiber recruitment after axotomy and regeneration. J Neurosci 30:16272-83

8. Malin SA, Molliver DC, Koerber HR, Cornuet P, Frye R et al (2006) Glial cell line-derived neurotrophic factor family members sensitize nociceptors in vitro and produce thermal hyperalgesia in vivo. J Neurosci 26:8588-99

9. Baloh RH, Tansey MG, Lampe PA, Fahrner TJ, Enomoto H et al (1998) Artemin, a novel member of the GDNF ligand family, supports peripheral and central neurons and signals through the GFRalpha3-RET receptor complex. Neuron 21:1291-302

10. Orozco OE, Walus L, Sah DW, Pepinsky RB, Sanicola M (2001) GFRalpha3 is expressed predominantly in nociceptive sensory neurons. Eur J Neurosci 13: 2177-82

11. Mcllvried LA, Albers K, Gold MS (2010) Distribution of artemin and GFRalpha3 labeled nerve fibers in the dura mater of rat: artemin and GFRalpha3 in the dura. Headache 50:442-50
12. Meents JE, Hoffmann J, Chaplan SR, Neeb L, Schuh-Hofer S et al (2015) Two TRPV1 receptor antagonists are effective in two different experimental models of migraine. J Headache Pain 16:57

13. Nicoletti P, Trevisani M, Manconi M, Gatti R, De Siena G et al (2008) Ethanol causes neurogenic vasodilation by TRPV1 activation and CGRP release in the trigeminovascular system of the guinea pig. Cephalalgia 28:9-17

14. Perrotta A, Serrao M, Tassorelli C, Arce-Leal N, Guaschino E et al (2011) Oral nitric-oxide donor glyceryl-trinitrate induces sensitization in spinal cord pain processing in migraineurs: a double-blind, placebo-controlled, cross-over study. Eur J Pain 15:482-90

15. Greco R, Ferrigno A, Demartini C, Zanaboni A, Mangione AS et al (2015) Evaluation of ADMA-DDAH-NOS axis in specific brain areas following nitroglycerin administration: study in an animal model of migraine. J Headache Pain 16:560

16. Tassorelli C, Greco R, Morocutti A, Costa A, Nappi G (2001) Nitric oxide-induced neuronal activation in the central nervous system as an animal model of migraine: mechanisms and mediators. Funct Neurol 16:69-76

17. Zhu X, Han Y, Xiong W, Liu W, Lu S et al (2011) Effects of heating coagulation of middle meningeal artery on plasma CGRP level and c-fos expression in migraine rat triggered by nitroglycerin. Neurol Sci 32:589-94

18. Sances G, Tassorelli C, Pucci E, Ghiotto N, Sandrini G et al (2004) Reliability of the nitroglycerin provocative test in the diagnosis of neurovascular headaches. Cephalalgia 24:110-9

19. Tassorelli C, Joseph SA (1995) Systemic nitroglycerin induces Fos immunoreactivity in brainstem and forebrain structures of the rat. Brain Res 682:167-81

20. Greco R, Tassorelli C, Cappelletti D, Sandrini G, Nappi G (2005) Activation of the transcription factor NF-kappaB in the nucleus trigeminalis caudalis in an animal model of migraine. Neurotoxicology 26:795-800

21. Reuter U, Bolay H, Jansen-Olesen I, Chiarugi A, Sanchez del Rio M et al (2001) Delayed inflammation in rat meninges: implications for migraine pathophysiology. Brain 124:2490-502

22. Shinoda M, Takeda M, Honda K, Maruno M, Katagiri A et al (2015) Involvement of peripheral artemin signaling in tongue pain: possible mechanism in burning mouth syndrome. Pain 156:2528-37

23. Kim GM, Jin KS, Chung CS (2008) Differential effects of corticosteroids on the expression of cyclooxygenase-2, tumour necrosis factor-alpha and matrix metalloproteinase-9 in an animal model of migraine. Cephalalgia 28 : 1179-87

24. Olesen J, Iversen HK, Thomsen LL (1993) Nitric oxide supersensitivity: a possible molecular mechanism of migraine pain. Neuroreport 4:1027-30

25. Elitt CM, Malin SA, Koerber HR, Davis BM, Albers KM (2008) Overexpression of artemin in the tongue increases expression of TRPV1 and TRPA 1 in trigeminal afferents and causes oral sensitivity to capsaicin and mustard oil. Brain Res 1230:80-90

26. Elitt CM, Mcllwrath SL, Lawson JJ, Malin SA, Molliver DC et al (2006) Artemin overexpression in skin enhances expression of TRPV1 and TRPA1 in cutaneous sensory neurons and leads to behavioral sensitivity to heat and cold. J Neurosci 26:8578-87

27. Kilo S, Harding-Rose C, Hargreaves KM, Flores CM (1997) Peripheral CGRP release as a marker for neurogenic inflammation: a model system for the study of neuropeptide secretion in rat paw skin. Pain 73:201-7

28. Bowles WR, Flores CM, Jackson DL, Hargreaves KM (2003) beta 2-Adrenoceptor regulation of CGRP release from capsaicin-sensitive neurons. J Dent Res 82 308-11

29. Zakharov A, Vitale C, Kilinc E, Koroleva K, Fayuk D et al (2015) Hunting for origins of migraine pain: cluster analysis of spontaneous and capsaicin-induced firing in meningeal trigeminal nerve fibers. Front Cell Neurosci 9:287

30. Summ O, Holland PR, Akerman S, Goadsby PJ (2011) TRPV1 receptor blockade is ineffective in different in vivo models of migraine. Cephalalgia 31:172-80

31. Davis JB, Gray J, Gunthorpe MJ, Hatcher JP, Davey PT et al (2000) Vanilloid receptor-1 is essential for inflammatory thermal hyperalgesia. Nature 405:183-7 